\title{
An open-source equipment for thin film fabrication by electrodeposition, dip coating, and SILAR
}

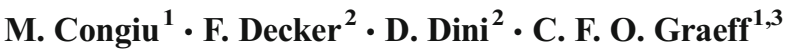

Received: 20 January 2016 / Accepted: 23 March 2016/Published online: 6 April 2016

(C) Springer-Verlag London 2016

\begin{abstract}
A reliable and cheap equipment is hereby proposed for the deposition of thin films on several substrates. This system is capable of deposition using three different techniques sequentially on the same substrate. The techniques available are ionic layer adsorption and reaction (SILAR), electrodeposition, and dip coating on both rigid and flexible conductive substrates (FTO, ITO-PEN). Using low-cost electronic components, we built a working prototype, driven by a simple software that is open source and user-friendly. In order to test our system, we used it to fabricate dye-sensitized solar cells (DSSCs) and counter electrodes of platinum and cobalt sulfide using both rigid glass-FTO and flexible ITO-PEN substrates. The electrodes as well as the complete devices have been characterized through cyclic voltammetry (CV). The solar cell devices have been characterized through current versus voltage curves $(I-V)$ under simulated solar illumination.
\end{abstract}

Electronic supplementary material The online version of this article (doi:10.1007/s00170-016-8680-7) contains supplementary material, which is available to authorized users.

M. Congiu

mirko.congiu@fc.unesp.br

1 Programa de Pós-Graduação em Ciência e Tecnologia de Materiais (POSMAT), Universidade Estadual Paulista (UNESP), Av. Eng. Luiz Edmundo Carrijo Coube14-01, 17033-360 Bauru, SP, Brazil

2 Department of Chemistry, University of Rome "La Sapienza", Piazzale Aldo Moro 5, Rome, RM, Italy

3 DC-FC, Universidade Estadual Paulista UNESP, Av. Eng. Luiz Edmundo Carrijo Coube14-01, 17033-360 Bauru, SP, Brazil
Keywords SILAR · Successive ionic layer adsorption and reaction $\cdot$ Dip coating $\cdot$ Electrodeposition $\cdot$ Open source . GNU equipment

\section{Introduction}

Material science is one of the most extensive and varied research fields. In fact, the search for newer, smarter, and cheaper materials embraces different fields of technology such as energy production and storage, electronics, and medicine. Thin film and semiconductor technologies become very important in many sectors of the modern industry. In fact, the functioning of many electronic devices is based on semiconductor thin films. Some clear examples of commonly used devices based on thin films are transistors [1], OLEDs [2], biosensors [3, 4], opto-electronic devices, and solar cells [5-8]. In the field of solar cells, the quality of the active semiconductor films is crucial for good functioning and energyharvesting performance $[9,10]$. In the industry of thin films, there are several commonly used techniques, such as electrodeposition (ED) [11, 12], which consists of growing a solid material on the surface of a conductive substrate by means of a redox reaction, induced by the application of current or voltage [13]. Another widespread deposition technique is dip coating (DC), which consists of coating a solid substrate surface by successive submersion into a solution or a suspension of the desired material [14]. Another important and widespread technique is the successive ionic layer adsorption and reaction, also known as SILAR. The substrate is alternatively dipped in two or more different solutions $[15,16]$. In this way, a solid insoluble film is grown by means of chemical reaction between anions and cations adsorbed on the surface. In most cases, the fabrication of a thin film-based device requires the use of different deposition techniques. In fact, many devices 
are composed of several layers of different materials. A good example of a multilayer device is the dye-sensitized solar cell (DSSC) $[17,18]$. A DSSC is typically composed of (1) a porous $\mathrm{TiO}_{2}$ nanocrystalline layer, (2) a strong colored molecule (dye) anchored to the surface of the $\mathrm{TiO}_{2}$, and (3) a redox electrolyte dissolved in a solvent or gel and a counter electrode (CE). The counter electrode generally consists of a thin layer of platinum nanoparticles deposited on conductive fluorinedoped tin oxide (FTO). The layer of $\mathrm{TiO}_{2}$ also known as photoanode can be prepared by screen printing, sol gel, or dip coating [19-21]. On the other hand, the CEs can be fabricated by screen printing, drop casting, sputtering, chemical vapor deposition, or electrodeposition [6, 22-24]. For these reasons, the complete fabrication of a DSSC, as well as other multilayer devices, requires the use of different equipment and thus a high investment. Most scientific equipment is sold with proprietary software, developed specifically to the instrument's functions. Furthermore, the software is closed and thus it is very difficult to add a custom function. Open source is the widespread philosophy of free software and operational systems (OS). This kind of software is distributed for free, and the user can modify the source code in order to improve or add other functions to the program. However, open source is not so common in scientific instruments. This results in great limitations if one needs to use a custom experimental configuration. Hereby, we propose a new solution in order to solve the problem of multi-equipment in the field of thin film deposition. Our equipment allows performing SILAR, electrodeposition, and dip coating sequentially. We used a cheap electronic component and an Arduino board, based on the microcontroller ATmega238, equipped with a serial port for the communication with an external current/voltage source. The software that controls the equipment is written in $\mathrm{C}$ and is provided in the Electronic supplementary material. The equipment described in this paper has been used to fabricate platinum and cobalt sulfide counter electrodes as well as complete DSSC, with energy conversion efficiencies comparable to those found in the literature.

\section{Materials and methods}

Titanium dioxide powder (Degussa P25), cobalt(II) chloride hexahydrate $\left(\mathrm{CoCl}_{2} \cdot 6 \mathrm{H}_{2} \mathrm{O}\right)$, titanium(IV) isopropoxide (TIPP), sodium sulfide $\left(\mathrm{Na}_{2} \mathrm{~S}\right)$, hexachloroplatinic acid $\left(\mathrm{H}_{2} \mathrm{PtCl}_{6}\right)$, N719 dye $\left(\mathrm{C}_{58} \mathrm{H}_{86} \mathrm{~N}_{8} \mathrm{O}_{8} \mathrm{RuS}_{2}\right)$, and all of the solvents were purchased from Sigma-Aldrich; the high-stability electrolyte (HSE-bv12) for DSSC was obtained from Dyers, Italy, and the indium tin oxide-covered polyethylene naphthalate (ITO-PEN) plastic sheet $\left(15 \Omega \mathrm{cm}^{-2}\right)$ from Peccell Technologies, Inc. The FTO/glass substrates (7 $\Omega \mathrm{cm}^{-2}$ ) have been purchased from Sigma-Aldrich. The HSE electrolyte was used for electrochemical impedance spectroscopy (EIS) characterizations. The measurements were performed using an Autolab PGStat 300, equipped with a FRA32. EIS spectra were collected between $100 \mathrm{kHz}$ and $10 \mathrm{mHz}$, using a $10-\mathrm{mV}$ single sine wave and an offset of $0 \mathrm{~V}$. Flexible platinum cathodes were prepared following the procedure proposed by Fu et al. [24]. Briefly, the ITO-PEN substrate was cut in rectangles $(1 \times 2 \mathrm{~cm})$ and thoroughly rinsed with water, ethanol, and acetone. Then, a water solution $5 \mathrm{mM} \mathrm{H}_{2} \mathrm{PtCl}_{6}$ containing $0.1 \mathrm{M}$ of $\mathrm{LiClO}_{4}$ supporting electrolyte was prepared. A platinum wire counter electrode was immersed in the solution. The equipment was set in galvanostatic electrodeposition mode, and two pulses of current were applied: the first pulse has an amplitude of $-1.5 \mathrm{~mA}$ and a duration of $5 \mathrm{~s}$; the second pulse has an amplitude of $-1.0 \mathrm{~mA}$ with a duration of $30 \mathrm{~s}$. After the deposition, the electrodes were rinsed with ethanol and dried. Flexible photoanode was prepared following the procedure related by Kim et al. [20]. A dip-coating $\mathrm{TiO}_{2}$ paste was prepared dispersing $10 \mathrm{~g}$ of $\mathrm{P} 25$ nanopowder with $86.8 \mathrm{~g}$ of ethanol and $1.4 \mathrm{~g}$ of distilled water. A homogeneous suspension was obtained after $30 \mathrm{~min}$ of ultrasonication $(1 \mathrm{~kW}) ; 1.8 \mathrm{~g}$ of TIPP was added and the suspension was kept under mild stirring for about $5 \mathrm{~h}$. The equipment was set in dip-coating mode, and the ITO-PEN substrates were dipped four times into the slurry and dried in air for $15 \mathrm{~min}$. The as-deposited films were annealed in a convection oven at $120{ }^{\circ} \mathrm{C}$ for $1 \mathrm{~h}$. The photoanodes were immersed in a solution $0.3 \mathrm{mM}$ of $\mathrm{N} 719$ dye for $25 \mathrm{~h}$ and then washed with ethanol and dried in an oven at $60{ }^{\circ} \mathrm{C}$. Then, the counter electrode was sealed with the photoanode using a hotmelt spacer (Surlyn). The HSE electrolyte was injected into the cell by vacuum backfilling. The as-prepared DSSC was characterized through $I-V$ curves under simulated sunlight (1 sun AM1.5).

Cobalt sulfide counter electrodes were prepared though the SILAR deposition method on both flexible ITO-PEN and FTO-covered glass slides. In the first vessel, a $50-\mathrm{mM}$ solution of $\mathrm{CoSO}_{4}$ was prepared dissolving the salt in distilled water. In the same way, in another vessel, a 50-mM solution of $\mathrm{Na}_{2} \mathrm{~S}$ was prepared. SILAR deposition was performed dipping the substrate alternatively in the two precursor solution vessels, with an intermediate washing step with distilled water. The as-deposited $\mathrm{CoS}$ films were sintered in a convection oven at $120^{\circ} \mathrm{C}$ during $2 \mathrm{~h}$. Symmetric dummy cells were assembled with two identical electrodes facing one another. The HSE electrolyte was used for the CV and EIS characterizations. Cyclic voltammetry was performed using an Autolab PGStat 300.

\section{Results and discussion}

The instrumentation, shown in Fig. 1, consists of (A) a mechanical arm that collects and operates the substrates. On the 
Fig. $13 \mathrm{D}$ representation of the equipment: mechanical arm $(A)$, rotary support $(B)$, solutions vessels $(C)$, autosampler for the substrate $(D)$ and the final product $(E)$, LCD display $(F)$, and an automatic clamp system for sample handling $(G)$

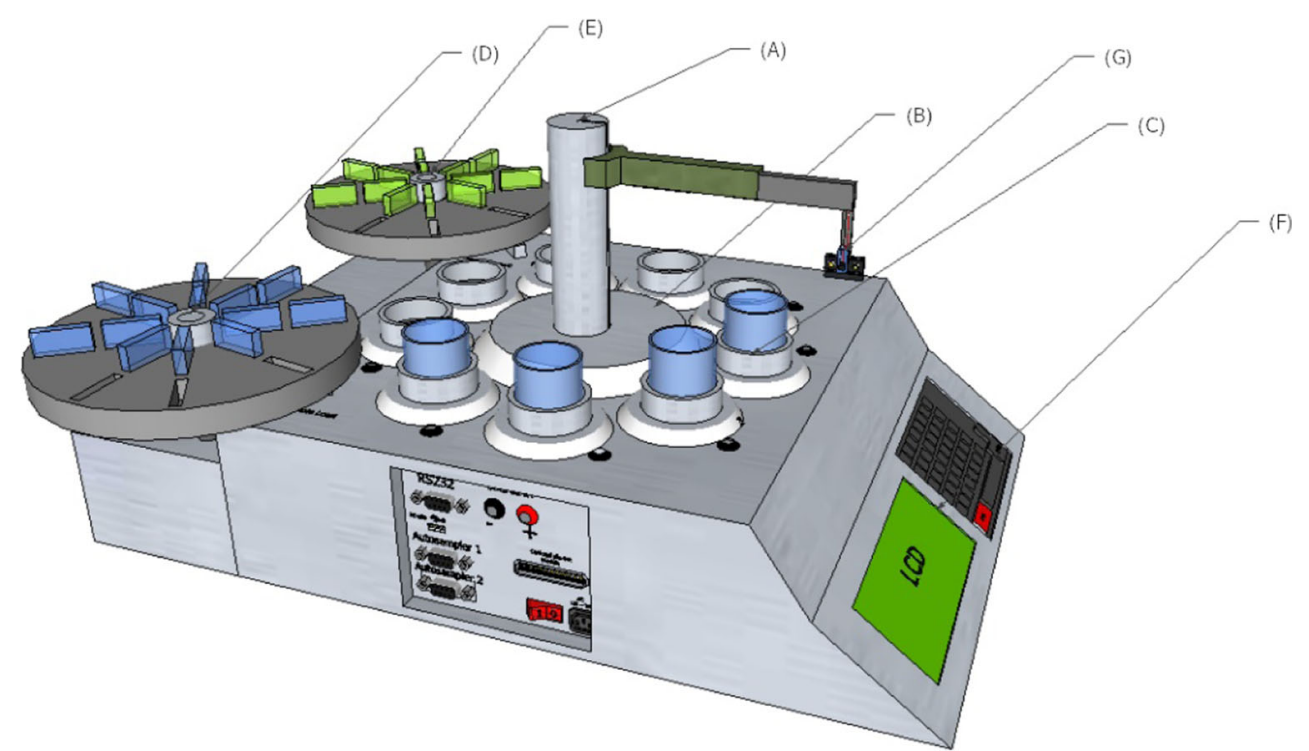

top surface (B), there are supports for the vessels containing the solutions of the materials (or precursors) to be deposited (C). The mechanical arm operates on three axes- $X, Y$, and $Z$ - combining servo and step motors. The mechanical arm can be fabricated using two different configurations according to user needs. For example, in Fig. 1, a system is shown which operates through a mechanical arm located in the center of a rotary support (B) and the vessels are arranged radially. Two autosamplers (D, E) are responsible for providing new substrates to the system and for removing the final product after the end of the deposition. The automatic sampling device consists of two round turntables. In Fig. 1, one can see an example of the autosampler, wherein there are two hubs: one for the substrate and another for the final product.

Another configuration for the mechanical arm is represented in Fig. 2, where the clamp system is located on top. The automatic clamp moves along a three-axis (XYZ) frame, moved by step motors. Using this configuration, one can use the whole space of the top surface for accommodating the solution vessels. Such configuration is suggested in the case of processes needing a high number of different deposition steps.

A fundamental part of this equipment is the automatic clamp, represented in Fig. 3. This part is responsible for sample handling from the beginning to the end of the deposition process. Furthermore, the clamp must provide the electrical contact with the surface of the sample in order to perform the electrodeposition. A metal clip (D) as shown in Fig. 3 provides the electrical contact.

All of the mechanical and electronic parts of the equipment are driven by a low-cost microcontroller (Arduino 2500 Mega). The internal software was developed using a virtual breadboard environment (VBB), which allows the use of both Java and $C$ commands. In order to perform $E D$, the microcontroller was connected to the Keithley $2400 \mathrm{C}$ through serial communication (MAX232). The commands from the Standard Commands for Programmable Instruments (SCPI) have been sent to the source/multimeter, writing on the serial
Fig. $23 \mathrm{D}$ representation of the equipment with the mechanical arm located in a $X Y Z$ moving frame. This configuration allows the processing of a higher number of samples and chemical solutions

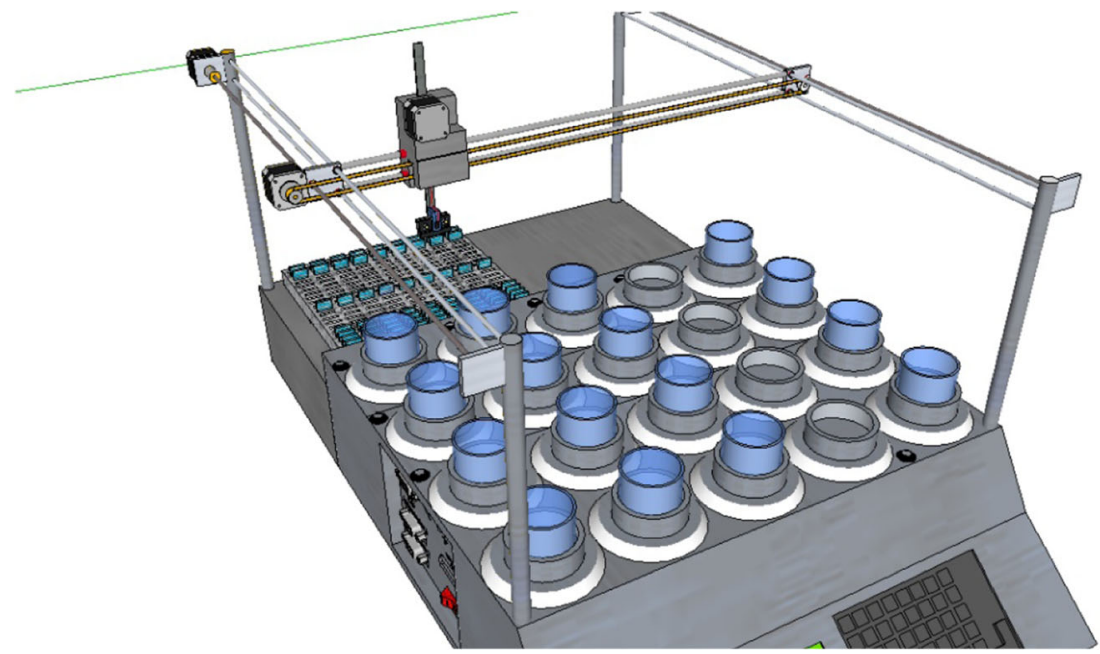



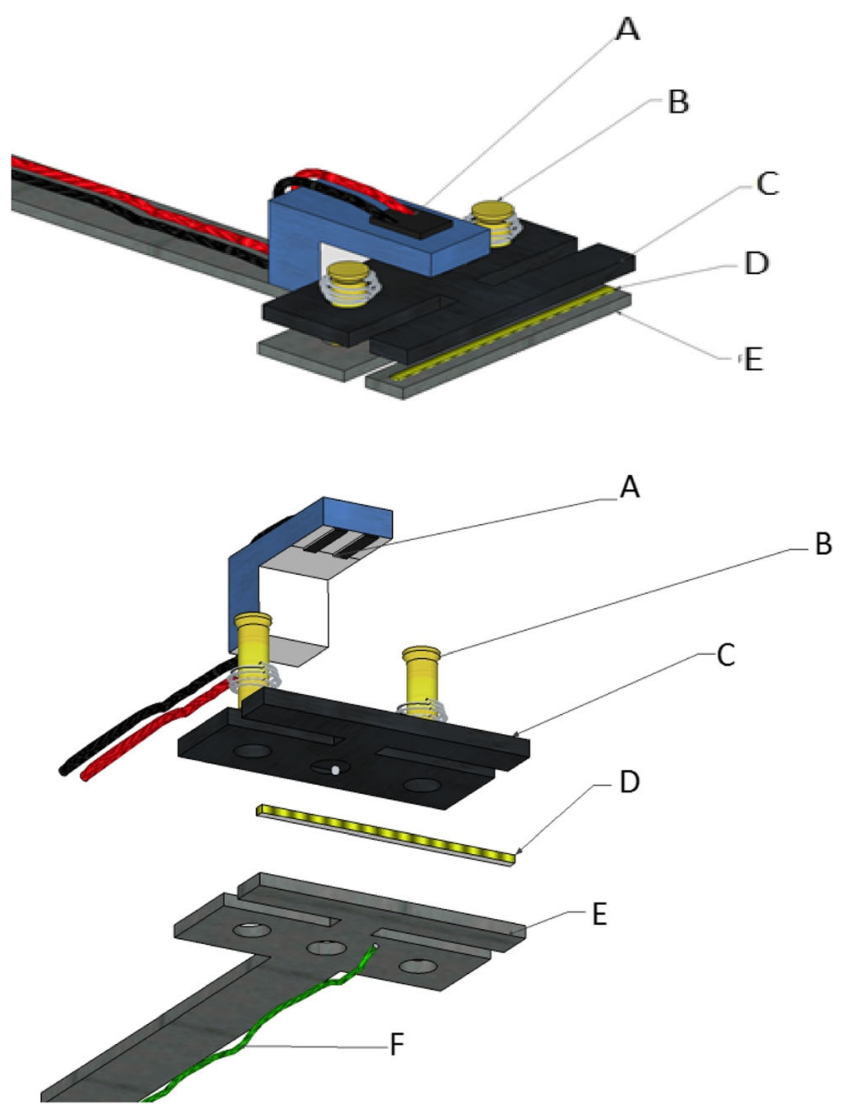

Fig. 3 Representation of the automatic clamp: the electromagnet $(A)$ attracts the superior plate $(C)$ in order to open the clamp. Straight pivots $(B)$ with metal springs ensure the clamp closure. A metal clip is responsible for the electrical contact $(D)$, connected to the current/ voltage source though the wire $(F)$; the bottom plate $(E)$ is made of insulating material. The opening and closing mechanism of the clamp consists of an electromagnet $(A)$, which attracts the top metallic plate $(B)$. When the electromagnet is switched off, the plate $(A)$ slides along two straight pivots $(B)$ by means of the pressure exerted by the metal springs in the pivots port a string object. Other models of the current/voltage source can be used, selecting the appropriate SCPI command's lists in the software. In Fig. 4, one can see the schematic view of the equipment. All of the operation and functions are controlled by the ATmega microcontroller. The input commands can be provided through two different channels (A and B). The default channel (A) consists of hardware buttons directly connected to the controller which allow to set up the experiment. All of the operations can be displayed on the LCD. It is possible to drive the equipment using an external computer. In this case, one can switch to channel (B). The internal software combines all of the parameters into a deposition routine. The deposition consists of a series of mechanical movements that move the sample from a pot to another or in the same pot (dip coating). During the deposition, if chosen in the setup, the microcontroller can send specific SCPI commands through the TTL channels $\left(R_{\mathrm{X}}\right.$ and $\left.T_{\mathrm{X}}\right)$. The output passes through a TTL to the RS232 transducer which allows the communication between the equipment and the voltage/current source.

All of the operations are controlled by the internal software, provided in the Electronic supplementary material, which can be divided into three main blocks as shown in Fig. 5. The first block contains the graphic user interface (GUI 1) for the setup of the experiment and the experimental variables, which are stored in a 2D array (matrix). Each row of the matrix represents a pot while the variables are organized into columns. The second block contains a routine that checks and counts the number of pots in which the electrodeposition must be performed. This routine is based on a loop function that reads the last column of the matrix starting from the first pot. In this column, a variable says to the program if the selected pot contains an ED function. If no electrodeposition is selected, the program automatically jumps to the third block, and then the user is asked to select the values of current or voltage for the selected pot using the GUI 2.
Fig. 4 Schematic view of the equipment. This configuration allows the execution of SILAR, dip coating, and electrodeposition. In fact, a current/voltage source is connected to the microcontroller through the RS232 port

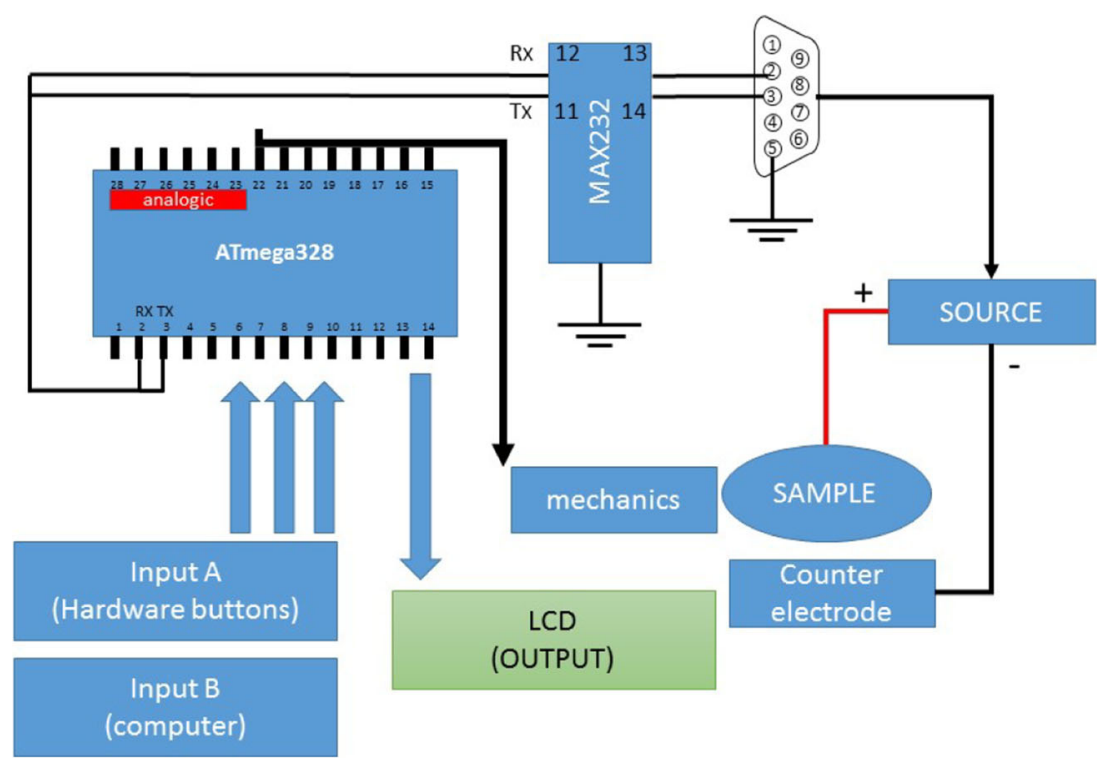


Fig. 5 Block representation of the internal software. The first block contains the graphic user interface for the setup of the experiments. The second block allows the configuration of the electrodeposition parameters, and the third block contains the code for the mechanical movements and the serial communication for the current/voltage application

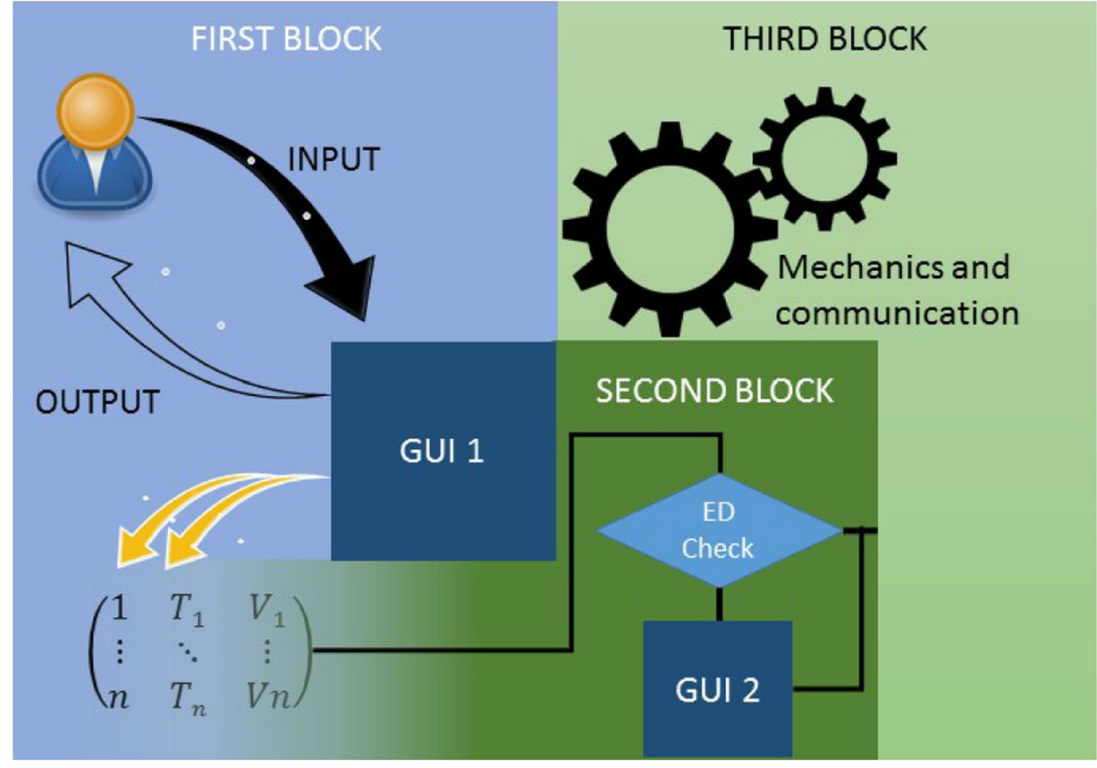

The third block contains all instructions to perform the mechanical movements such as dipping and the transfer of the sample from a pot to another. The operations in the fourth block can be repeated (loop); in this way, several deposition cycles can be applied on a sample. The software is open source so other users can use, share, and modify following the same philosophy of a GNU project. So parts of the source code can be edited and improved; furthermore, the user can use the code to build different and customized equipment. The software allows also the implementation of different input interfaces such as Bluetooth or Wi-Fi connection to control the equipment with a smartphone. In Table 1, one can see the comparison between our equipment and other equipment proposed so far.

As shown in Table 1, other similar deposition instruments have been proposed so far in the literature. An automatic dipcoating system was proposed by LeCompte and Tonazzi. In this equipment, the deposition tanks were equipped with a novel system for maintaining constant the substrate covering even as the level of the solution drops [25]. Another interesting and cheap dip-coating equipment was proposed by Oliveira and Zarbin in 2005. This configuration allows the deposition of a single sample at a time [26]. Among the electrodeposition equipment, Jaramillo et al. in 2005 proposed an automatic deposition system to grow a thin layer of $\mathrm{Zn}_{1-x} \mathrm{Co}_{x} \mathrm{O}$. Using a mechanical $x y z$ system connected to a potentiostat, the equipment allows the growth of thin oxide films through the electrodeposition technique [27]. All of the equipment discussed above allows the realization of a single deposition technique (electrodeposition or dip coating). In this direction, the equipment we proposed within this paper offers the possibility to realize electrodeposition, dip coating, and SILAR simultaneously on the same sample. Also, we implemented an autosampling system (Figs. 1 and 2) in order to make the processes automatic and continuous. Notice that, the equipment proposed in [27] and in [26] do not provide any autosampling system; therefore, in the presence of a human operator, it is necessary to give continuity to the deposition process when several samples have to be fabricated. Another advantage of the proposed equipment is the open-source philosophy behind the internal software, which allows the users to modify and improve their own systems according to their objectives. The microcontroller used in the fabrication of the prototype (ATmega238) provides the necessary computing power to perform the mechanical movements and to handle all of the system's variables used by the internal software. It is important to notice that the reliability of the system, in the application of correct current/voltage output values, depends on the coupled source. In the proposed equipment, we coupled a Keithley 2400 C, which provides reliability in nonstop production environments, as guaranteed by the manufacturer.
Table 1 Comparison between the equipment proposed in this work and similar equipment proposed so far in the literature

\begin{tabular}{llllll}
\hline Equipment & $\begin{array}{l}\text { Dip } \\
\text { coating }\end{array}$ & SILAR & Electrodeposition & $\begin{array}{l}\text { Open } \\
\text { source }\end{array}$ & Reference \\
\hline Dip-coating system & Yes & No & No & No & {$[25]$} \\
Dip-coating system & Yes & No & No & No & {$[26]$} \\
Automated electrodeposition system & No & No & Yes & No & {$[27]$} \\
Automated SILAR, ED, and dip coating & Yes & Yes & Yes & Yes & This work \\
\hline
\end{tabular}


Fig. 6 Cyclic voltammograms of symmetric dummy cells filled with iodine-based HSE electrolyte. The measurements have been performed with a scan rate of $100 \mathrm{mV} \mathrm{s}^{-1}$

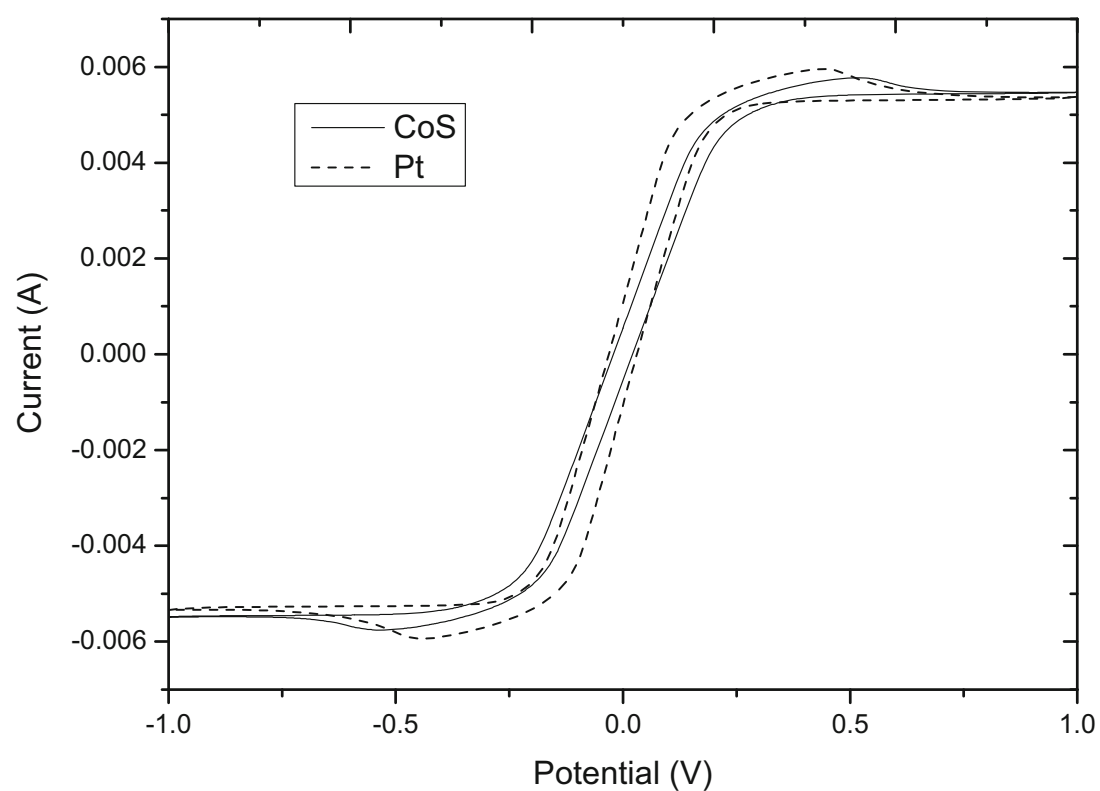

\subsection{Results of the experiments}

The equipment shows interesting performance in the production of thin films for solar energy application. In fact, Pt and $\mathrm{CoS}$ counter electrodes for DSSCs have been prepared on both flexible ITO-PEN and FTO using the proposed equipment. The as-deposited electrodes showed high efficiency with the iodine-based electrolyte for DSSC. The cyclic voltammetry response of two typical dummy cells of $\mathrm{CoS}$ and $\mathrm{Pt}$ electrodes on FTO is shown in Fig. 6.

As shown in Fig. 6, both Pt and CoS counter electrodes showed a perfect reversibility of the $\Gamma / I_{3}{ }^{-}$redox couple. In the dummy cell with $\operatorname{CoS}$ counter electrodes, the values of the anodic and cathodic limit currents $\left(I_{1}\right)$ were 5.46 and $5.48 \mathrm{~mA}$ respectively. The same values using Pt counter electrodes were 5.32 (anodic) and 5.44 (cathodic). A perfect reversibility was observed also using flexible electrodes. As shown in Fig. 7, narrow hysteresis CV curves were observed in the flexible dummy cells. Notice that as explained in the previous section, in this case, no spacers have been used.

In the case of plastic conductive substrates, one can observe a lower slope in both traces in comparison to what is observed using FTO. This can be due to the lower conductivity of ITO-PEN.

In order to characterize the charge transfer behavior of the asprepared counter electrodes, EIS measurements have been performed on dummy cells filled with the iodine-based electrolyte for
Fig. 7 Cyclic voltammetry of symmetric flexible dummy cells with HSE electrolyte. The scan rate for those measurements was $100 \mathrm{mV} \mathrm{s}^{-1}$. The two identical electrodes were located one facing the other without spacer

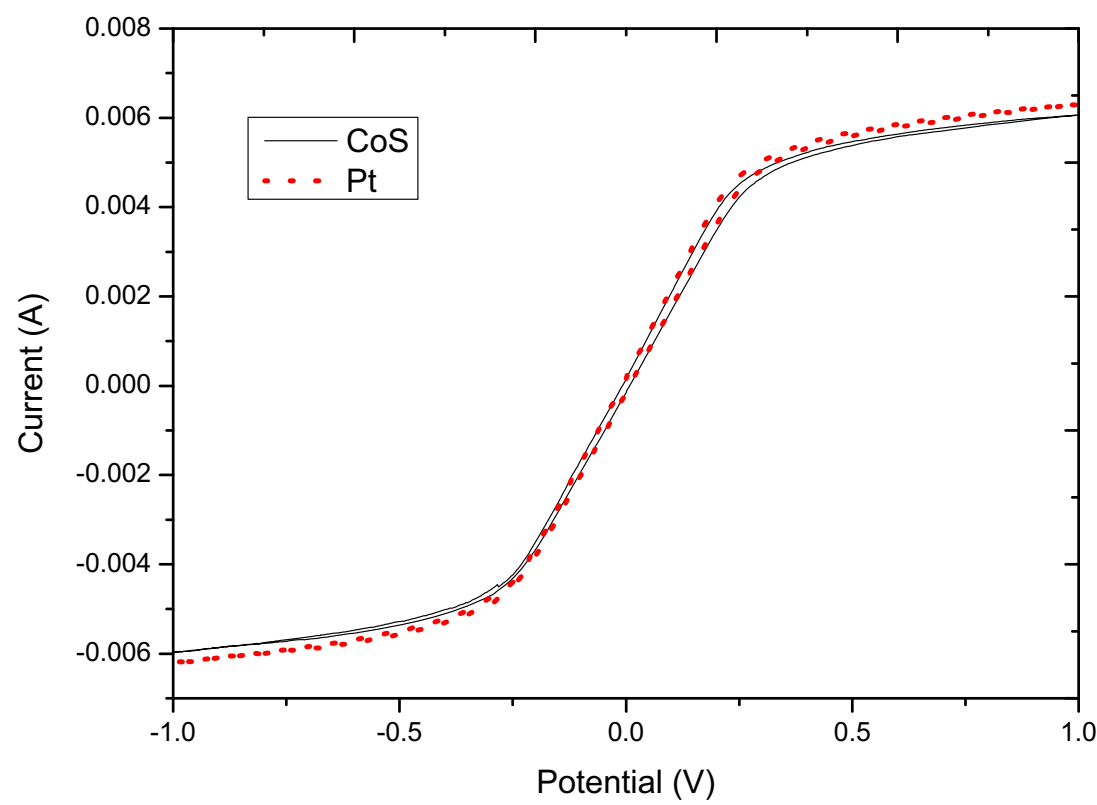




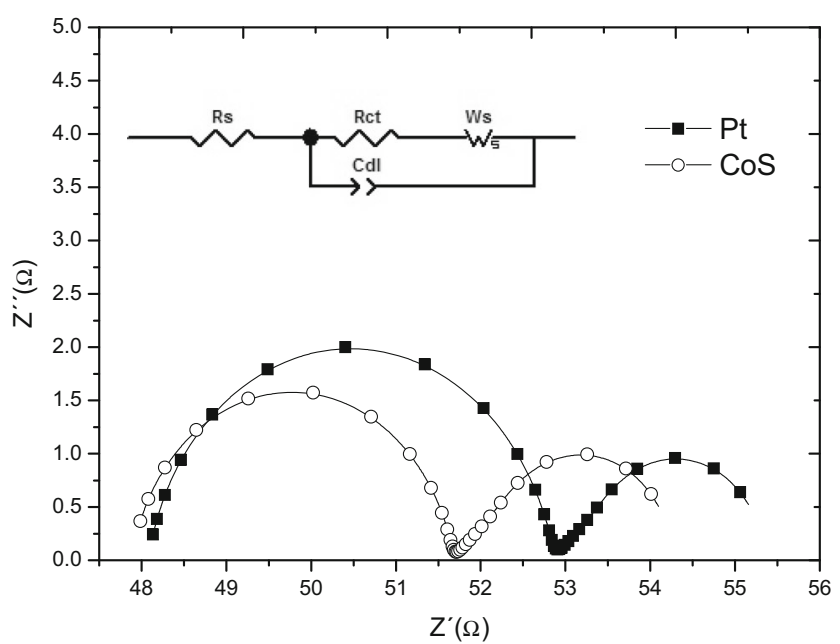

Fig. 8 EIS spectra of two typical dummy cells with CoS (empty circle) and $\mathrm{Pt}$ (filled square) counter electrodes fabricated with the proposed equipment. The measurements were performed at $0 \mathrm{~V}$ offset, applying a $10-\mathrm{mV}$ DC from $100 \mathrm{kHz}$ to $10 \mathrm{mHz}$. In the graph, the equivalent circuit is also shown consisting of a series resistance $\left(R_{\mathrm{S}}\right)$, a charge transfer resistance $\left(R_{\mathrm{ct}}\right)$, a Warburg finite length diffusion $\left(W_{\mathrm{s}}\right)$, and a parallel capacitor $C_{\mathrm{d} l}$

DSSC (HSE). The experimental data were fitted with an equivalent circuit, using Zview 2.0, in order to calculate the electrochemical parameters of the dummy cells such as the series resistance $\left(R_{\mathrm{s}}\right)$, the charge transfer resistance $\left(R_{\mathrm{ct}}\right)$, the double layer capacitance $\left(C_{\mathrm{dl}}\right)$, and the Warburg finite ion diffusion $\left(W_{\mathrm{s}}\right)$. The impedance response (Nyquist plots) and the equivalent circuit of dummy cells are represented in Fig. 8 .

The real part of the impedance in the complex plane $\left(Z^{\prime}\right)$ represents the values of electrical resistance of the electrode. On the other hand, capacitances and inductances, related to the charge transfer process at the interface of the electrode, are treated as imaginary numbers $\left(Z^{\prime \prime}\right)[28,29]$. The charge transfer resistance of CoS counter electrodes $\left(1.89 \Omega \mathrm{cm}^{2}\right)$ resulted lower than that of $\mathrm{Pt}$ (Table 2). This is due to a faster charge transfer kinetic with the iodine/iodide redox couple, typical of $\operatorname{CoS}[6,7,30,31]$. It is confirmed also by the value of the capacitance $\left(18 \mu \mathrm{F} \mathrm{cm}{ }^{-2}\right)$, which is lower than that of the platinum $\left(28 \mu \mathrm{F} \mathrm{cm}^{-2}\right)$. Notice that the relaxation time of the system can be estimated multiplying $R_{\mathrm{ct}}$ and $C_{\mathrm{dl}}$ according to the Debye model [28]. The lower the relaxation time (time constant), the faster the charge transfer kinetic. A similar pattern was observed with the electrodes fabricated using rigid FTO-glass substrates.

In this case, a lower series resistance was observed for both Pt and CoS CEs due to the higher conductivity of the FTO. Notice that in a dye solar cell, a low value of $R_{\mathrm{ct}}$ at the cathode (counter electrode) is preferable. In fact, in a typical n-type DSSC, the cathode is a passive element; thus, the lower the value of $R_{\mathrm{ct}}$, the lower its influence on the overall resistance to the current flow through the device [7, 32]. In Table 3, the asmeasured values of $R_{\mathrm{ct}}$ are compared with those obtained in the literature using different equipment.

As shown in Table 3, the proposed equipment was compared with Autolab PGStat 300 and 320N (Metrohm). Notice that Autolab is a potentiostat/galvanostat commonly used in electrochemistry research. It allows a fine control of the applied current $( \pm 0.0003 \%$ of the current range). However, Autolab does not provide any specific solution for the automated deposition of thin films, and its cost is very high if compared with the equipment we proposed, which can be fabricated using low-cost electronics (ATmega microcontrollers) and open-source software. Using flexible ITO-PEN substrates, the value of $R_{\mathrm{ct}}$ calculated for Pt counter electrodes was $2.38 \Omega \mathrm{cm}^{2}$, close to that obtained by Fu et al. using Autolab PGStat $300\left(2.10 \Omega \mathrm{cm}^{2}\right)$ [24]. Also, the Pt counter electrodes deposited on glass-FTO conductive substrates show a little value of $R_{\mathrm{ct}}\left(2.19 \Omega \mathrm{cm}^{2}\right)$, close to the value obtained by Wang et al. $\left(2.20 \Omega \mathrm{cm}^{2}\right)$ using Autolab PGStat 300 [32]. Cobalt sulfide counter electrodes, deposited by SILAR, showed a $R_{\mathrm{ct}}$ value of $1.58 \Omega \mathrm{cm}^{2}$ slightly higher than that obtained by Lin et al. using Autolab PGStat N320 $\left(1.03 \Omega \mathrm{cm}^{2}\right)$ [33] but lower than that reported by Srinivasa Rao et al. (3.52 $\left.\Omega \mathrm{cm}^{2}\right)$ using chemical bath deposition and common laboratory glassware [34]. In order to evaluate the dip-coating performance of the proposed equipment, porous $\mathrm{TiO}_{2}$ photoanodes were deposited on flexible ITO-PEN substrate. Complete flexible DSSCs have been assembled using the electrodeposited $\mathrm{Pt}$ cathode and the dip-coated $\mathrm{TiO}_{2}$ photoanode. In Fig. 9, the current/voltage response of a typical flexible DSSC is shown. As one can see, the cells, in the best conditions, showed good PV characteristics with FF of $50.3 \%$, a $J_{\text {sc }}$ of $4.05 \mathrm{~mA} / \mathrm{cm}^{2}$, a $V_{\text {oc }}$ of $655 \mathrm{mV}$, and an energy conversion efficiency of $1.34 \%$.
Table 2 Fitted electrochemical parameters of flexible (ITO-PEN) and rigid (FTO-glass) dummy cells. All of the parameters have been calculated starting from EIS spectra; series and charge transfer resistances $\left(R_{\mathrm{s}}, R_{\mathrm{ct}}\right)$; double layer capacitance $\left(C_{\mathrm{d} 1}\right)$ and the CPE exponent $n$; Warburg resistance, time constant, and exponent $\left(W_{\mathrm{r}}, W_{\mathrm{t}}\right.$, and $W_{\mathrm{p}}$ )

\begin{tabular}{lllllrrr}
\hline Electrode/substrate & $R_{\mathrm{s}}\left(\Omega \mathrm{cm}^{2}\right)$ & $R_{\mathrm{ct}}\left(\Omega \mathrm{cm}^{2}\right)$ & $C_{\mathrm{dl}}\left(\mu \mathrm{F} \mathrm{cm} \mathrm{cm}^{-2}\right)$ & $n$ & $W_{\mathrm{r}}(\Omega)$ & $W_{\mathrm{t}}(\mathrm{s})$ & $W_{\mathrm{p}}$ \\
\hline Pt/ITO-PEN & 48.08 & 2.38 & 28 & 0.952 & 2.55 & 11.03 \\
CoS/ITO-PEN & 47.88 & 1.89 & 18 & 0.893 & 2.62 & 10.11 \\
Pt/FTO-glass & 9.72 & 2.19 & 31 & 0.991 & 3.47 & 0.48 \\
CoS/FTO-glass & 9.07 & 1.58 & 17 & 0.882 & 4.21 & 9.92 \\
\hline
\end{tabular}


Table 3 Comparison between $\mathrm{CoS}$ and Pt counter electrodes fabricated with different equipment and techniques. The charge transfer resistance $\left(R_{\mathrm{ct}}\right)$, calculated through electrochemical impedance spectroscopy (EIS), was considered as a comparison parameter. The cell configuration was the same in all of the experiments: dummy cell with two identical electrodes using the redox couple $\Gamma / I_{3}{ }^{-}$(HSE)

\begin{tabular}{lllll}
\hline Electrode/substrate & Technique & Equipment & $R_{\mathrm{ct}}\left(\Omega \mathrm{cm}^{2}\right)$ & 2.38 \\
Pt/ITO-PEN & Electrodeposition & This work & 2.10 & This work \\
Pt/ITO-PEN & Electrodeposition & Autolab PGStat 300 & 2.19 & {$[24]$} \\
Pt/FTO-glass & Electrodeposition & This work & 2.20 & This work \\
Pt/FTO-glass & Electrodeposition & Autolab PGStat 300 & 1.58 & {$[32]$} \\
CoS/FTO-glass & SILAR & This work & 1.03 & This work \\
CoS/FTO-glass & Electrodeposition & Autolab PGStat 320N & 3.52 & {$[33]$} \\
CoS/FTO-glass & CBD & Laboratory glassware & {$[34]$} & \\
\hline
\end{tabular}

$C B D$ chemical bath deposition

The sharp voltammograms obtained for both the solid FTO and flexible ITO substrates indicate that the kinetics of the redox reactions at the surface of the electrodes is fast and comparable to that shown by platinized counter electrodes. Furthermore, according to Ohm's law, a high slope of the curve implies also a small resistance at the interface electrode/electrolyte $(I=V / R)$. The flexible DSSC, fabricated using the proposed equipment, shows an efficiency comparable to that of similar devices reported so far in the literature, ranging from 1.24 to $1.96 \%$ according to the observations of Kim and Hwang [20].

\section{Conclusions}

In this paper, a cheap and reliable equipment has been proposed. The equipment is based on cheap and common

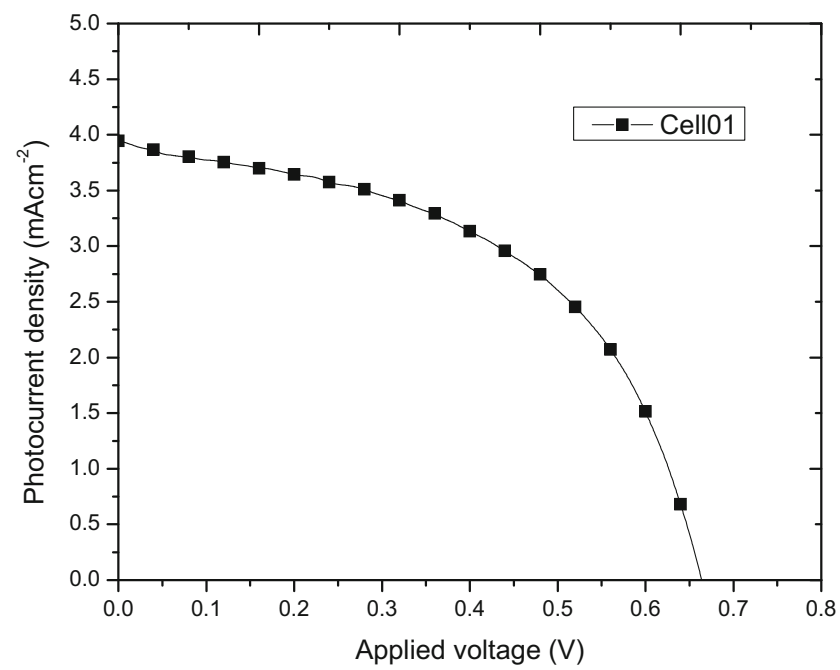

Fig. 9 Current versus voltage response of a typical flexible DSSC. The flexible photoanodes have been dip-coated from a suspension of $\mathrm{TiO}_{2}$ nanoparticles. The cathodes have been electrodeposited from a solution of $\mathrm{H}_{2} \mathrm{PtCl}_{6}$. The measurements have been performed under simulated sunlight (1 sun, AM1.5) electronic and mechanical components and its assembly does not require special techniques. This equipment is original and not yet described so far in the literature. In this research work, we showed three different examples of application in the field of solar energy materials. All of the prepared materials showed good efficiency and characteristics comparable to those obtained so far in the literature. So the proposed solution could be very promising for reducing the investment of a research laboratory or an industry that is going to start to work with thin films technology. In our prototype, we used an ATmega microcontroller; however, other devices could be considered. Notice that no border problems have been encountered using a different substrate. If the user were to use a thicker or larger substrate, both the clamp and the vessels should be scaled up. Furthermore, this equipment could open different possibilities of innovative research. In fact, it could be used for hybrid deposition techniques such as SILAR or dip coating with the application of pulsed current or potential, a research field not yet explored. So, we encourage other scientists dealing with the multi-instrument problem to apply the open-source philosophy to make their custom equipment. In this way, other technological and practical problems should be solved in other research fields.

Acknowledgments This work was supported by FAPESP (Fundação de Amparo à Pesquisa do Estado de São Paulo), Processo FAPESP: 2013/07396-7. We especially thank Mr. Luiz Meneghetti Jr. and all of the members of LNMD of UNESP of Bauru (SP)-Brazil for the technical support. We thank the University of Rome La Sapienza for having allowed the use of its facilities.

\section{References}

1. Kagan CR, Andry P (2003) Thin-film transistors. CRC, Boca Raton

2. Ghosh AP, Gerenser LJ, Jarman CM, Fornalik JE (2005) Thin-film encapsulation of organic light-emitting devices. Appl Phys Lett 86: 223503. doi:10.1063/1.1929867 
3. Tsai Y-C, Li S-C, Chen J-M (2005) Cast thin film biosensor design based on a nafion backbone, a multiwalled carbon nanotube conduit, and a glucose oxidase function. Langmuir 21:3653-3658

4. Piacenti da Silva M, Fernandes JC, de Figueiredo NB et al (2014) Melanin as an active layer in biosensors. AIP Adv 4:037120. doi: 10.1063/1.4869638

5. Chae SY, Hwang YJ, Choi J-H, Joo O-S (2013) Cobalt sulfide thin films for counter electrodes of dye-sensitized solar cells with cobalt complex based electrolytes. Electrochim Acta 114:745-749. doi: 10.1016/j.electacta.2013.10.038

6. Congiu M, Albano LGS, Decker F, Graeff CFO (2015) Single precursor route to efficient cobalt sulphide counter electrodes for dye sensitized solar cells. Electrochim Acta 151:517-524. doi:10. 1016/j.electacta.2014.11.001

7. Congiu M, Lanuti A, di Carlo A, Graeff CFO (2015) A novel and large area suitable water-based ink for the deposition of cobalt sulfide films for solar energy conversion with iodine-free electrolytes. Sol Energy 122:87-96. doi:10.1016/j.solener.2015.08.032

8. Chopra KL, Das SR (1983) Why thin film solar cells? Springer, New York

9. Hodes G (2013) Perovskite-based solar cells. Science 342:317-318

10. AbdulAlmohsin S, Mohammed M, Li Z et al (2012) Multi-walled carbon nanotubes as a new counter electrode for dye-sensitized solar cells. J Nanosci Nanotechnol 12:2374-2379

11. Clark D, Wood D, Erb U (1997) Industrial applications of electrodeposited nanocrystals. Nanostruct Mater 9:755-758

12. Brenner A (2013) Electrodeposition of alloys: principles and practice. Elsevier, Amsterdam

13. Podlaha-Murphy E (2011) Molecular structure of the solid-liquid interface and its relationship to electrodeposition 7: ECS Transactions: volume 33

14. Scriven LE (2011) Physics and applications of DIP coating and spin coating. MRS Proc 121:717. doi:10.1557/PROC-121-717

15. Sakka S (2005) Handbook of sol-gel science and technology. 1. Sol-gel processing. Springer Science \& Business Media

16. Nicolau YF (1985) Solution deposition of thin solid compound films by a successive ionic-layer adsorption and reaction process. Appl Surf Sci 22-23:1061-1074. doi:10.1016/0378-5963(85)90241-7

17. O’Regan B, Gräzel M (1991) A low-cost, high-efficiency solar cell based on dye-sensitized colloidal $\mathrm{TiO}_{2}$ films. Nature 353:737-740

18. Mathew S, Yella A, Gao P et al (2014) Dye-sensitized solar cells with $13 \%$ efficiency achieved through the molecular engineering of porphyrin sensitizers. Nat Chem 6:242-247

19. Ito S, Chen P, Comte P et al (2007) Fabrication of screen-printing pastes from $\mathrm{TiO} 2$ powders for dye-sensitised solar cells. Prog Photovolt Res Appl 15:603-612. doi:10.1002/pip.768

20. Kim H, Hwang T (2014) Effect of titanium isopropoxide addition in low-temperature cured TiO2 photoanode for a flexible DSSC. J SolGel Sci Technol. doi:10.1007/s10971-014-3427-0
21. Lan J-L, Wang Y-Y, Wan C-C et al (2010) The simple and easy way to manufacture counter electrode for dye-sensitized solar cells. Curr Appl Phys 10:S168-S171. doi:10.1016/j.cap.2009.11.064

22. Zhang B, Wang D, Hou Y et al (2013) Facet-dependent catalytic activity of platinum nanocrystals for triiodide reduction in dyesensitized solar cells. Sci Rep 3:1836. doi:10.1038/srep01836

23. Mgabi LP, Dladla BS, Malik MA et al (2014) Deposition of cobalt and nickel sulfide thin films from thio- and alkylthio-urea complexes as precursors via the aerosol assisted chemical vapour deposition technique. Thin Solid Films 564:51-57. doi:10.1016/j.tsf. 2014.04.086

24. Fu N, Xiao X, Zhou X et al (2012) Electrodeposition of platinum on plastic substrates as counter electrodes for flexible dye-sensitized solar cells. J Phys Chem C 116:2850-2857. doi:10.1021/jp206676s

25. LeCompte R, Tonazzi J (2003) Deep coating system. PATENT, $\mathrm{N}^{\circ}$ US20030077396, 24 April 2003. http://www.google.ch/patents/ US20030077396

26. Oliveira ARM, Zarbin AJG (2005) Um procedimento simples e barato para a construção de um equipamento "dip-coating" para deposição de filmes em laboratório. Quim Nov. 28:141-144

27. Jaramillo TF, Baeck S-H, Kleiman-Shwarsctein A et al (2005) Automated electrochemical synthesis and photoelectrochemical characterization of $\mathrm{Zn} 1-\mathrm{xCoxO}$ thin films for solar hydrogen production. J Comb Chem 7:264-271

28. Barsoukov E, Macdonald JR (2005) Impedance spectroscopy: theory, experiment, and applications. Wiley, Hoboken

29. Bard A, Faulkner L (2001) Electrochemical methods: fundamentals and applications. Wiley, New York

30. Lin J-Y, Liao J-H, Wei T-C (2011) Honeycomb-like CoS counter electrodes for transparent dye-sensitized solar cells. Electrochem Solid-State Lett 14:D41-D44

31. Yang J, Bao C, Zhu K, Yu T, Li F, Liu J, Li Z, Zou Z (2014) High catalytic activity and stability of nickel sulfide and cobalt sulfide hierarchical nanospheres on the counter electrodes for dye-sensitized solar cells, Journal: Chem Commun (Cambridge, England), 50(37):4824 4826. doi:10.1039/c4cc00001c

32. Wang M, Anghel AM, Marsan B et al (2009) CoS supersedes Pt as efficient electrocatalyst for triiodide reduction in dye-sensitized solar cells. J Am Chem Soc 131:15976-15977

33. Lin J-Y, Liao J-H, Chou S-W (2011) Cathodic electrodeposition of highly porous cobalt sulfide counter electrodes for dye-sensitized solar cells. Electrochim Acta 56:8818-8826. doi:10.1016/j. electacta.2011.07.080

34. Srinivasa Rao S, Gopi CVVM, Kim S-K et al (2014) Cobalt sulfide thin film as an efficient counter electrode for dye-sensitized solar cells. Electrochim Acta 133:174-179. doi:10.1016/j.electacta.2014.04.010 